\title{
The Usefulness of Patent Stage and Sectoral Pattern in Open Innovation Licensing
}

\author{
Junyoung Kim (I), Yongtae Park (2)
}

\begin{abstract}
The relative importance to the particular industry of licensing has not been done enough empirically to pursue the route of the open innovation. That is why the industrial level research on open innovation is more complicated than that of company level. This paper tries to survey industrial level licensing by combining the technology regime theory with NTB(National Technology Bank) score model of KTTC(Korea Technology Transfer Center) and tries to transform Likert score into general value proxy by using information of valuator's organizations. This paper also introduces two new factors named as 'patent authorization stage' for classifying patent status and 'technology regime based industrial innovation pattern' for adopting sectoral level research in order to overcome drawbacks of score model in case of application to open innovation licensing.
\end{abstract}

Keywords: score model, patent, innovation, sector, pattern.

(I) Technology, Management, Economics and Policy, Seoul National University, San 56-I, Shillim-Dong, Kwanak-Gu, I5I-742, Seoul, Korea.

Jykim0I@snu.ac.kr

(2) Industrial Engineering, Seoul National University, San 56-I, Shillim-Dong, Kwanak-Gu, I5I-742, Seoul, Korea. parkyt@cybernet.snu.ac.kr. 


\section{Introduction}

According to the open innovation papers written by Chesbrough (2002; 2003), Chesbrough and Rosenbloom (2002), and Chesbrough and Vanhaverbeke (2006), easy transfer of the core capabilities involved in R\&D and massive knowledge transfer via various channel (Dunning, 198I; Balasubramanyam, 1973) such as colleges and research institutes can make the major changes in the R\&D process of a company, providing that knowledge are traded as normal commodity (Eisenhardt, 1989). In more detail, those changes can be classified into two categories. The first is that a company can make value added by the idea not only from the inside, but also from the outside channel away from the current business area (Pisano, 1990). The second is that production process can follow the routes not only of the inner closed feedback process, but also of the business model from the outside through outbound innovations (Kirschbaum, 2005).

Therefore, under the open innovation paradigm, business model has a significant meaning to a company. Moreover, in some cases, the idea from the outside can be taken into consideration more than the idea from the inside. IP(Intellectual Property)-management is emphasized so that a particular company can make profit or develop a business model by acquiring or licensing the technologies of the other company when it is necessary. But, the research works related to the industrial characteristics surrounding the business environments, and the relative importance to the particular industry of intellectual properties, especially patent, has not been done enough empirically to pursue the route of the open innovation. There is Pavitt(1984)'s empirical research work on the industrial level of innovation that is independent of technology regime. He categorized industry into the four types of supply-dominated, scale-intensive, specialized supplier, and science-based. This classification implies itself the possibility of open innovation in industry level, linking the technological factors such as the source and protection of technology to the size of a company (Kassicieh et al., 2002). However, to consider the size of a company for the study of open innovation in the corporate level will lose the flexibility of application. Therefore, it is necessary to redefine industry based on the fundamental technological regime theory explaining the industrial open innovation probability via licensing. This paper is to try to combine the technology regime theory and Pavitt's classification in order to identify open innovation characteristics in industry level and try to apply its empirical usefulness using the transformation value proxy of NTB(National Technology Bank) data of KTTC(Korea Technology Transfer Center) in Korea.

\section{Theoretical background}

\section{I Technology regime}

The phenomena that technology innovation occurs as a cluster gathered around a particular technology region is called a technology paradigm by Dosi (1988), and called guide post by Sahal (198I), and called technology regime by Nelson and Winter (1977). According to Tushman and Rosenkof (1992), the technological innovation paradigm made by radical innovation is accompanied by a rapid increase of technological opportunities. Or vice versa, technology innovation itself is one of the phenomena caused by a lot of technological opportunities (Dosi, 1988). Whether technology innovation is pushed by technology or pulled by demand (Schmookler, 1996), the formation of new paradigm generally leads to the increase of technological opportunities. The technology paradigm or regime can be understood in the level of industry. Malerba and Orsenenigo (1996; 1997; 1999), Breschi et al. (2000) studied the innovation system in the level of industry. These industrial changes of paradigm have been described with technological opportunity of environment, systematical knowledge base of industry, and technology cumulative property (Daghfous, 2004) and appropriability of the firm within the industry.

\section{I.I Technology opportunity}

In general, how much the technological opportunities are reflects how possible it is for the technology innovation to succeed when R\&D is invested with fund (Breschi et al. 2000). Four independent dimensions are suggested here, one of which is the level of opportunities. This level can be described as high or low. For example, in case it is highly probable that technology innovation would succeed when a certain amount of money is invested, the technological opportunities can be described as high (Buratti and Penco, 200I). The second one is diversity. Plenty of available technologies, approaches and activities lead to a high level of technological opportunities. The third one is pervasiveness. Large pervasiveness means that the knowledge generated from new technologies can be applied to various products and markets (Lee and Win, 2004). The fourth one is the sources of innovation (Hur and Watanabe, 2002) which are science, the innovation of equipment supplied from the outside, and learning within a company. The first and second one is related to the frequency of product innovation, and the third and fourth one is related to the stability of the direction which the technology trajectory follows.

Two major types of technology innovation are product innovation and process innovation (Abernathy and Utterback, 1978). 
These innovations generally proceed incrementally. Generally, the frequency of occurrence between product and process innovations varies as the industrial development stages of fluid, transition, and specific period. Frequent product innovations mean that the product belongs to the early stage of industrial development, in which new paradigm is being tried and applied to products and processes. Therefore, the frequency of occurrence of product innovation can be used when technological opportunities are described in relation with technology innovations.

The technology innovation paradigm to create technology opportunities has the characteristics ruled not only by the technology itself, but also by the path dependency (Niosi et al., 1993) according to history. Almost every technology innovation procedure is, based on the path of the past, to add and combine new technological factors, and finally to form a new technology innovation paradigm (Christensen and Bower, 1996). Nelson and Winter (1977) focused on the fact that the path dependency and the technology innovation paradigm keep the route of some bounded direction, and called the route as a technology trajectory. From these characteristics, technological opportunities are concerned with the stability of the technology trajectory, in which a paradigm forms and evolves.

\subsubsection{Cumulative property}

The technology innovation is the outcome of a cumulative process. In almost every technology innovation, small scale improvements accumulate for a long period leading to a radical innovation. The fact that technology innovation is cumulative can be explained by the inherent property of knowledge, because technology is actually mapped into knowledge. Bower and Hilgard (1980) ascertain that the personal learning capability is greatly enhanced, when the personally owned prior cumulative knowledge is highly concerned with the new knowledge. Cohen and Levinthal (1990), who extended the personal learning to the level of company, viewed that under a certain paradigm a company begins to learn simple technological knowledge, and gradually gets the ability to absorb more complex technological knowledge. If this absorptive capacity improves, the amount of knowledge learning increases, later on results in the generation of a large scale technological change (Lazonick, 1993; Eliasson, 1992). A company continuing its production activity transforms technological skills into tacit or explicit knowledge of the organization (Polanyi, 1966), keeps improving the functions and management capabilities to achieve the goal of sales and profits. In this process, technological knowledge go through the process of trial and error, and get feed-backed to the organization in order to adapt to the outer environmental changes(Kale et al., 2000), and the organization pursues a new change(Rosenberg, 1976). The learning pattern occurring in this case is the organization interactive learning. The interactive learning is the most important characteristics in a technology innovation process (Daghfous, 2004), and is the cause to bring the cumulative characteristics of the technology innovation (Garavelli et al., 2002).Therefore, the cumulative property also means how probable a company would succeed in a technology innovation in the market for the next period of time based on the absorptive capability for new technologies, when a company succeeds in a technology innovation for a particular period of time (Nicholls-Nixon, 1993).

\subsection{3 .Appropriability}

Appropriability is a condition related to the possibility to keep the result of technology innovation from being imitated by others (Breschi et al., 2000) and the profit resulting from innovation (Teece, 1986). Grant (1996) regarded appropriability as the characteristics of knowledge, which is used for value generation by a company.Appropriability is difficult to be taken wholly by a technology innovator, because technology is intangible and is not easily possessed like a normal commodity. Specifically, when it comes to more scientific sort of knowledge, to attain appropriability is too difficult to achieve commercial profit. Therefore, by allowing the exclusive right to hold appropriability through patents which are effective within a certain limited period of time, public benefit and private right come to the trade off.The tool to hold appropriability for the result of technology innovation could be the explicit knowledge type one like patents accompanying legal protection, or could be the tacit knowledge type one like sales secret and lead time of production, etc which are distributed and shared inside a company (Nonaka, 1994; Nonaka and Takeuchi, 1995). When a technology innovation paradigm is formed and stabilized, technological competitions get deepened, but the possibility to succeed in commercializing new technologies becomes so high that the commercial effectiveness of R\&D increases automatically (Rogers et al., 200I). In this environment, technology innovation becomes incremental, and costs less gradually. Considering this procedure, after a technology paradigm is formed, it can be viewed that the effect of the appropriability for new technologies could be enhanced.

\section{I.4. Systematical knowledge base}

In general, products and processes are composed of an interrelated hierarchical system (Metcalfe, 1990). Innovation could be the change of individual parts, the change of the structure combining parts, or both of them. Henderson and Clark (1990) considered in details these systematical technological innovation which lies between incremental and radical innovation. They called the innovation not influencing the whole structure of the system but specifically changing one or more parts as 
modular innovation. However, in contrast with that, they called changing the design of whole system or the way of interaction among the constituent parts as architectural innovation. The reason why the systematical viewpoint on technology is important is that only to be equipped with the knowledge of the components is enough for a company to begin or accept modular innovation, the architectural innovation further asks a company to have knowledge of the whole structure, such as network structure of each part, and the way to constitute the whole. In this way, the knowledge base is related to system technology. The Complex Product System that is recently studied extending these systematical approaches to industry level is distinguished to have the characteristics of systematical complication from the goods of mass production(M. Hobbday, 1998). Hughes (1982)'s prior research analyzing a large scale of systematical technology summarized its characteristics. So the concept of systematical complexity can be defined from the aspects, such as the number of the produced parts to meet the demand, need knowledge, the depth of skill, the new knowledge needed to production. Therefore, it is important that technology regime has the characteristics of systematical knowledge base.

\section{Data preparation}

\section{I Evaluation categories of NTB}

The evaluation scoring model used by the National Technology Bank (NTB: a subsidiary of Korea Technology Transfer Center) for licensing technology can be explained by the general technology regime theory in Table I.The main reason for popularity of scoring model is due to its simplicity and robustness. However, scoring model is subject to critical drawbacks. First, score itself never tells the real meaning of value so we should transform it into value proxy via information economy. Second, the structural relationship between technology factor and market factor not only is ignored but also is overlapping and redundant with respect to technology regime theory.

Table I. Evaluation factors of NTB with respect to technology regime theory.

\begin{tabular}{lll}
\hline Evaluation category & Evaluation sub categories & Technology regime categories \\
\hline \multirow{2}{*}{ Technology innovativeness } & Pevel of technology & Appropriability \\
& Reliability of technology & Cumulative property \\
& Technology infrastructure & Appropriability \\
& Possibility of substitutive technology & Cumulative property \\
Technology & Scope of Apply & Systematical knowledge base \\
competitiveness & Completeness of support & Technology opportunity \\
& Diversity of market & Technology opportunity \\
Market characteristics & Characteristics of market & Systematical knowledge base \\
Competition & Type of competition & Technology opportunity \\
characteristics & Existence of entry barrier & Cumulative property \\
Easiness of & Size of initial investment cost & Technology opportunity \\
commercialization & Condition of raw material logistics & Appropriability \\
& Expecting ROl(Return On lnvestment) & Cumulative property \\
\hline
\end{tabular}

The 336 technologies in this study chosen from the released one in 'NTB recommended technology' are evaluated by the Likert criterion of 5 and 6 scores about the above five evaluation categories by appointed 18 valuation experts, the most probable to be licensing, registered from August I 2005 to May
222006 supplied by KTTC. The technical statistics of the evaluated technology are in the table 2.All the 336 technologies do not show a big difference in the distribution of the five eva-luation categories. 
Table 2. Descriptive statistics

\begin{tabular}{lccccc}
\hline & $\mathrm{N}$ & Min & Max & Mean & SD \\
\hline Technology innovativeness & 336 & 2 & 5 & 3.21 & 0.714 \\
Technology competitiveness & 336 & 1 & 5 & 3.40 & 0.643 \\
Market characteristics & 336 & 2 & 5 & 3.82 & 0.629 \\
Competition characteristics & 336 & 1 & 5 & 3.16 & 0.620 \\
Easiness of commercialization & 336 & 2 & 5 & 3.38 & 0.663 \\
\hline
\end{tabular}

Correlation analysis is performed to test the appropriateness of applying theoretical technology regime. It is analyzed through correlation analysis that the value of technology is appropri- ately evaluated by five evaluation categories. The result of the correlation analysis is shown in Table 3.

Table 3. Correlation analysis

\begin{tabular}{|c|c|c|c|c|}
\hline & $\begin{array}{l}\text { Technology } \\
\text { innovativeness }\end{array}$ & $\begin{array}{l}\text { Technology } \\
\text { competitiveness }\end{array}$ & $\begin{array}{l}\text { Market } \\
\text { characteristics }\end{array}$ & $\begin{array}{l}\text { Competition } \\
\text { characteristics }\end{array}$ \\
\hline $\begin{array}{l}\text { Technology } \\
\text { competitiveness }\end{array}$ & $\begin{array}{l}0.431 \\
(0.000)\end{array}$ & & & \\
\hline Market characteristics & $\begin{array}{l}0.115 \\
(0.036)\end{array}$ & $\begin{array}{l}0.175 \\
(0.001)\end{array}$ & & \\
\hline $\begin{array}{l}\text { Competition } \\
\text { characteristics }\end{array}$ & $\begin{array}{l}0.269 \\
(0.000)\end{array}$ & $\begin{array}{l}0.391 \\
(0.000)\end{array}$ & $\begin{array}{l}0.056 \\
(0.308)\end{array}$ & \\
\hline $\begin{array}{l}\text { Easiness of } \\
\text { commercialization }\end{array}$ & $\begin{array}{l}0.324 \\
(0.000)\end{array}$ & $\begin{array}{l}0.328 \\
(0.000)\end{array}$ & $\begin{array}{l}0.154 \\
(0.005)\end{array}$ & $\begin{array}{l}0.169 \\
(0.002)\end{array}$ \\
\hline
\end{tabular}

*Pearson correlation (P-Value)

There are effective degrees of the correlations among all terms. So it can be understood that the correlations between evaluation sub categories are naturally brought from correlations of technology regimes categories. The correlations among some terms are low, for example 'Competition characteristics' and 'Market characteristics' has $p$ value 0.308 , but 'Technology innovativeness' and 'Technology competitiveness' shows more that 0.4 of correlation. The fact that there are some effective degrees of correlations among the opposite terms that should be independent of each other in accordance with technology regime categories(in table I.) indicate some problems in applying evaluation system, whether they are large or small. This means that if the valuator thinks an object is superior in some terms they commit a mistake by providing that the technology is superior in overall score and vice-versa, therefore each term of technology regime information is not exactly taken into consideration, which is viewed as a problem of agency.

\subsection{Value transformation using information economy}

To solve the valuator's agency problem, prior to empirical analysis, the Likert's chart composed of five evaluation categories provided by Korea Technology Bank is transformed to a proper value, in other words, technological value proxy by using the organization's information. This is to make the subjective evaluation of each valuator objective of which method is represented as the following equation.

$$
S_{i k}=\sum_{j=1}^{5} w_{i j} r_{b j}^{T}
$$

Where i means the organization that the investigators belong to, $j$ and $k$ mean evaluation term and evaluation technology, respectively, $w_{i j}$ is a weight averaged matrix of the $i$-th evaluation organization versus $\mathrm{j}$-th term, and $r_{k j}$ is an evaluation point matrix of the k-th technology versus j-th evaluation term. In case the valuator belonging to the $\mathrm{i}$-th organization evaluates the $\mathrm{k}$ th technology, the importance of the upper term of each evaluation organization multiplied by the technological value of each valuator is the technological value proxy. To keep objective property, by running AHP (Analytic Hierarchy Process) based on the survey including the 108 investigators of each concerned organization, the relative importance of factors of each organ- 
ization are calculated. To solve the agency problem, it is considered that the value factor regarded as important by each organization is based on the real information possessed by the organization. Through this transformation, technological value is represented as a real number within $[0,1]$.This value represents the proxy of technological value. As it approaches I, the technological value can be relatively regarded as high.

\begin{tabular}{lllll} 
Table 4. Weight averaged matrix of the i-th evaluation organization versus j-th evaluation term \\
\hline & $\begin{array}{l}\text { Public appraisal } \\
\text { organization }\end{array}$ & $\begin{array}{l}\text { Private } \\
\text { company }\end{array}$ & $\begin{array}{l}\text { Public Research } \\
\text { center } \\
\text { /University }\end{array}$ & $\begin{array}{l}\text { Private } \\
\text { appraisal } \\
\text { organization }\end{array}$ \\
\hline Technology innovativeness & 0.386 & 0.410 & 0.436 & 0.368 \\
Technology competitiveness & 0.114 & 0.107 & 0.179 & 0.147 \\
Market characteristics & 0.181 & 0.071 & 0.167 & 0.103 \\
Competition characteristics & 0.178 & 0.232 & 0.128 & 0.191 \\
Easiness of commercialization & 0.140 & 0.178 & 0.090 & 0.191 \\
\hline
\end{tabular}

\section{The factors for compensating licensing score model}

Because the prior NTB model of value evaluation structurally has the correlation among independent variables which should not have correlation in accordance with technology regime, and independency of 'Market characteristics' category. This cannot be applied directly to the score of open innovation licensing, and it is necessary to introduce the new theoretical variables, which maximally combine 'Market characteristics' factor and decouple 'Technology innovativeness' and 'Technology competitiveness' in accordance with technology regime theory. So, this paper is intended to use 'patent authorization stage' for dividing and 'technology regime based industrial innovation pattern' for combining. The patent authorization stage is the factor to evaluate the important 'cumulative property' and 'appropriability' in IP management in order to decide 'Technology innovativeness' before everything else. Technology regime based industrial innovation pattern is the factor to evaluate 'technological opportunities' and 'systematical knowledge base' in addition to 'patent authorization stage' and combining 'Technology competitiveness' with 'Market characteristics' affecting the business model controlling the possibility of open innovation.

\section{I Patent authorization stage}

According to the research of Nelson and Phelps (1966), companies recognize the importance of patent in sales, the effort on service, and the short lead-time to market, etc. In the aspect of the importance of patent, there exists a difference among industries, based on the fact that the type of the cumulative property of technology innovation could be different. In other words, the wider the range of patent claim to be protected by law is, the better it is (Kitch, 1977), or vice versa the narrower, the better (Merges and Nelson, 1990). That the range of patent claim is narrow corresponds to the fact that technology level (inventive step in terms of patent law) is described by a few explicit independent claims and a multitude of dependent claims based on the advancement of technology, and that the range is wide corresponds to the fact that technology is described as a type of a multitude of independent claims and a few dependent claims by extending the range of patent right. For example, for the type of patents combining patent of product and that of process for production, a multitude of independent claims are included. Especially supporting the narrow range of patent, Merges and Nelson exaggerated that the patents with wide range hinder the following technology development and reduce the varieties within industry. The research of patent data has been done in the three main groups, which are the NBER group composed of Griliches, Hall, Jaffe, Pakes, and Schankerman, and Schmookler simply regarding patents as complementary data for R\&D, and finally the rest group of Levin, Nelson, Klevorick, Winter, Reiss and Cohen focusing on the appropriation of patent. It can be viewed that the possibility of the contract could vary depending on whether the factor of IP management centered on open innovation is the patent of the corresponding technology or is simply a know-how as well as technology is differentiated with the know-how of tacit knowledge type by being authorized as the type of formal knowledge. Furthermore, in this paper, the proxies of the previously mentioned cumulative property and appropriability are supposed to be a variable of authorization stage. In this study, the authorization stage of patent being disregarded in the evaluation process of technological value is considered. 'Patent authorization stage' is a criterion composed of the case without patent, applying for patent, registration of utility (patent right of lower level inventive step), and patent registration. Beginning with the value of 0 in the case without patent, it has the values of $\mathrm{I}, 2$, and 3 . 


\subsection{Technology regime based industry innovation pat- tern}

The possibility of open innovation generally increases in the following cases.

Firstly, if a supplier has exclusive know-how, it will be better to attain it from the supplier that to develop it for a company. This case corresponds to the supplier-dominated company from Pavitt( 1984)'s classification, which the in-sourcing within industry decreases but the in-sourcing in the science based industry and scale intensive industry that are supplier industries increases. In this case, the medium level of appropriability can change into high level and high level of cumulative property to protect the prior technology become important.

Secondly, in case that in the process of technology development special expert knowledge is necessary and size economy is established because new manpower and resources are needed, it will be better to take in-sourcing and out-sourcing overall. Therefore, for scale-intensive industry 'systematical knowledge base' is important in licensing, and naturally the high level of cumulative property and the appropriability of the technology for production are important to enjoy relatively the size economical effect.

Thirdly, the case is that the supplier's technology is better and cheaper, and easier to be integrated into the prior system. This case is classified by Pavitt (1984) to be specialized supplier, in which the correlations with other industry are high, the technological trajectory of the industry itself is greatly stable, the frequencies of product innovation for system integration are important to licensing, and the high level of 'appropriability','cumulative property', and 'systematical knowledge base' of the technology are naturally important.

The fourth case is that technological opportunities are large. In this case, companies will choose the way of in-sourcing technology instead of developing technology for themselves. Companies will try to make in-sourcing of technology rather than to develop technology for themselves in case the cost of developing technology for themselves is bigger than of licensing technology with technological opportunities rapidly changing, and technology development has a difficulty to catch up with time to market due to the high frequency of product innovation. Generally, Science based industries have this kind of property. Therefore, for science-based firms technological opportunities (technological trajectory, product innovation frequency), the cumulative property and appropriability of technology, systematic knowledge base of technology are naturally important. As a result, licensing most likely occurs in science based firm. The discussions done so far are summarized in Table 5 .

Table 5. Relative importance of technology regime factor with respect to open innovation probability in Pavitt's classification

\begin{tabular}{|c|c|c|c|c|}
\hline & $\begin{array}{c}\text { Supplier } \\
\text { dominated }\end{array}$ & Scale intensive & Specialized supplier & $\begin{array}{c}\text { Science } \\
\text { base }\end{array}$ \\
\hline $\begin{array}{l}\text { Technological Opportunity } \\
\text { (frequency of occurrence of product } \\
\text { innovation, } \\
\text { stability of the technology trajectory) }\end{array}$ & & & medium & high \\
\hline Cumulative property & high & high & high & high \\
\hline Appropriability & medium & high & high & high \\
\hline Systematical knowledge base & & medium & high & high \\
\hline
\end{tabular}

It should be noted that table 5 displays the relative importance related with the open innovation of the factors of the technology regime among industries. For example, although from the aspect of technological opportunities every industry is somewhat significant, for the conventional agriculture and textile that is relatively supplier dominated, the innovation frequency is relatively low, and the variation of technological trajectory is also small so that technological opportunities are less important. Also, for specialized suppliers or scale intensive industries, technological trajectory is relatively more stable than it is for science based industries so that technological opportunities are regarded less significantly. From this aspect point of view, it can be viewed that telecommunication or bio science industries are classified into science based industry and software or measuring equipment industries correspond to the specialized supplier industry. In this paper, linking the sectoral pattern of innovation with the possibility of open innovation in accordance with related technology regime factor numbers, theoretically $I$ is allotted to the supplier dominated case, 2 is to the scale intensive case, 3 is to the specialized supplier case, and 4 is to the science based case. 


\section{Results and Discussion}

The analysis of variance (ANOVA) of the technology value proxy with respect to factors compensating licensing score model is performed. The results are displayed in table 6,7.As it can be seen from the results, for 'patent authorization stage' is valid for discriminating technology value, but the 'technology regime based industrial innovation pattern' that means the possibility of open innovation licensing in industry level is not valid because $p$-value is 0.091 .

\section{Table 6. Result of ANOVA with respect to patent authorization stage}

\begin{tabular}{|c|c|c|c|c|c|}
\hline Group & $\mathrm{N}$ & \multicolumn{2}{|c|}{ Mean } & \multicolumn{2}{|c|}{$\mathrm{SD}$} \\
\hline 1 & 61 & \multicolumn{2}{|c|}{0.56137} & \multicolumn{2}{|c|}{0.08621} \\
\hline 2 & 99 & \multicolumn{2}{|c|}{0.54329} & \multicolumn{2}{|c|}{0.08650} \\
\hline 3 & 14 & \multicolumn{2}{|c|}{0.51071} & \multicolumn{2}{|c|}{0.08228} \\
\hline 4 & 162 & \multicolumn{2}{|c|}{0.58003} & \multicolumn{2}{|c|}{0.08187} \\
\hline Source & $\mathrm{DF}$ & SS & MS & $\mathrm{F}$ & $\mathrm{P}$ \\
\hline Patent authorization stage & 3 & 0.12347 & 0.04116 & 5.82 & 0.001 \\
\hline Error & 332 & 2.34767 & 0.00707 & & \\
\hline Total & 335 & 2.47113 & & & \\
\hline
\end{tabular}

$* S=0.08409, R$-sq $=5.00 \%, R-s q(\operatorname{adj})=4.14 \%$

Table 7. Result of ANOVA with respect to technology regime based industry innovation pattern

\begin{tabular}{|c|c|c|c|c|c|c|}
\hline Group & $\mathrm{N}$ & & \multicolumn{2}{|c|}{ Mean } & \multicolumn{2}{|c|}{ SD } \\
\hline 1 & 65 & & \multicolumn{2}{|c|}{0.55386} & \multicolumn{2}{|c|}{0.07342} \\
\hline 2 & 58 & & \multicolumn{2}{|c|}{0.54166} & \multicolumn{2}{|c|}{0.06203} \\
\hline 3 & 88 & & \multicolumn{2}{|c|}{0.57029} & \multicolumn{2}{|c|}{0.09947} \\
\hline 4 & 125 & & \multicolumn{2}{|c|}{0.57233} & \multicolumn{2}{|c|}{0.08969} \\
\hline Source & & $\mathrm{DF}$ & SS & MS & $\bar{F}$ & $\mathrm{P}$ \\
\hline $\begin{array}{l}\text { Technology regime based } \\
\text { industrial innovation pattern }\end{array}$ & & 3 & 0.04752 & 0.01584 & 2.17 & 0.091 \\
\hline Error & & 332 & $2.4236 \mathrm{I}$ & 0.00730 & & \\
\hline Total & & 335 & 2.47113 & & & \\
\hline
\end{tabular}

This means that the 'patent authorization stage' fills the role of decoupling but 'technology regime based industrial innovation pattern' does that of combining. So we can conclude that the valuator usually score the technology regardless of asymmetry information. For example, if the evaluation technology has 'patent registration' then valuator regards it as high level of technology in open innovation licensing, scoring both 'Technology innovativeness' and 'Technology competitiveness' with high points. But it is not appropriate according to technology regime theory. We can clarify this situation more detail using logistic regression.

The logistic regression analysis that regards technological value proxy as a dependent variable and the evaluation categories of
NTB with two new terms as independent variables is performed. The results are in table 8, 9. The regression analyses are performed twice by varying samples. First of all, among the total 336 cases the logistic regression analysis to differentiate the technologies attaining higher technological values than average (the value of $I$ is allocated) from the technologies attaining lower technological values than average (the value of 0 is allocated) is performed. The result is shown in table $8 . \ln$ this case, it is shown that the entire prior five evaluation terms are valid, but the new evaluation terms of "patent authorization stage' and 'technology regime based industrial innovation pattern' are not valid. This shows that in the evaluation of the technology having more than the average level of all industries the prior five evaluation terms of NTB is somewhat appropriate. 
But, in table 9 only the term of 'technology regime based industrial innovation pattern' representing the possibility of open innovation for respective industries is disclosed to be valid under the confidence level of 0.05 from the result attained from evaluating the excellent technologies pertaining to the upper $25 \%$. This represents that the five evaluation terms are valid from the criterion of differentiating the technologies above ave- rage with the technologies below average, but are not good enough to discriminate the excellent technologies enabling open innovation licensing, and the evaluation term of the 'technology regime based industrial innovation pattern' confirming open innovation probability for respective industries can only be used in industry discriminate variable effectively.

Table 8. Result of logistic regression with respect to upper average technologies

\begin{tabular}{lcccc}
\hline Predictor & Coef & SE Coef & Z & P \\
\hline Constant & -175.755 & 48.8034 & -3.76 & 0.000 \\
Technology innovativeness & 119.664 & 32.1941 & 3.72 & 0.000 \\
Technology competitiveness & 50.2917 & 13.6512 & 3.68 & 0.000 \\
Market characteristics & 28.4877 & 0.28833 & 3.44 & 0.001 \\
Competition characteristics & 65.6792 & 19.3386 & 3.40 & 0.001 \\
Easiness of commercialization & 48.2945 & 13.2898 & 3.63 & 0.000 \\
Patent authorization stage & -0.828605 & 0.571301 & -1.45 & 0.147 \\
Technology regime based industrial & 0.554612 & 0.499931 & 1.11 & 0.267 \\
innovation pattern & & & &
\end{tabular}

Table 9. Result of logistic regression with respect to higher value proxy (25\% upper)

\begin{tabular}{lcccc}
\hline Predictor & Coef & SE Coef & Z & P \\
\hline Constant & -1131.41 & 17206.6 & -0.07 & 0.948 \\
Technology innovativeness & 542.815 & 9289.55 & 0.06 & 0.963 \\
Technology competitiveness & 316.673 & 9437.93 & 0.03 & 0.973 \\
Market characteristics & 205.197 & 4429.43 & 0.05 & 0.963 \\
Competition characteristics & 425.045 & 6997.87 & 0.05 & 0.952 \\
Easiness of commercialization & 310.614 & 7040.70 & 0.04 & 0.955 \\
Patent authorization stage & 0.0371423 & 0.731286 & 0.05 & 0.990 \\
Technology regime based industrial & -0.865867 & 0.428990 & -2.02 & 0.043 \\
innovation pattern & & & &
\end{tabular}

As a conclusion, we suggest that a valuator should regard the patent as a only 'Technology innovativeness' superiority by applying 'Patent authorization stage' and consider 'Market characteristics' as interrelated parameter in open innovation licensing by using 'Technology regime based industry innovation pattern'. So these can overcome the drawbacks of score model for open innovation licensing.

\section{References}

ABERNATHY, W.J., Utterback, J.M., (1978) Patterns of Innovation in Technology. Technology Review ,80, 40-47.

BALASUBRAMANYAM,V., ( 1973) International technology transfer to India. Praeger, New York

BOWER, G., Hilgard, E., (1980) Theories of learning. Fifth ed, Prentice-Hall, Englewood Cliffs, NJ
BRESCHI, S., Malerba, F., Orsenigo, L., (2000) Technological regimes and Schumpeterian patterns of innovation. The Economic Journal, I I0, 388-4I0.

BURATTI, N. and Penco, L., (200 I) Assisted technology transfer to SMEs: lessons from an exemplary case. Technovation, 2 I , 3543

CHESBROUGH, H., (2002) Making sense of corporate venture capital. Harvard Business Review, 80, 90-97.

CHESBROUGH, H., (2003) Open Innovation:The New Imperative for Creating and Profiting from Technology. Harvard Business School Press, Cambridge, MA.

CHESBROUGH, H., Rosenbloom, R., (2002) The role of the business model in capturing value from innovation: evidence from Xerox corporation's technology spin-off companies. 
Industrial and Corporate Change, I I, 529-555

CHESBROUGH, H., Vanhaverbeke, W., West, J., (2006) Open Innovation: Researching a New Paradigm. Oxford University Press, Oxford

CHRISTENSEN, C.M. Bower, J.L., (1996) Customer Power, Strategic Investment, and the Failure of Leading Firms. Strategic Management Journal ,17, 197-218

COHEN, W.M., Levinthal, D.A., (1990) Absorptive capacity: a new perspective on learning and innovation. Administrative Science Quarterly, 35, I28-152.

DAGHFOUS,A., (2004) An empirical investigation of the roles of prior knowledge and learning activities in technology transfer. Technovation, 24, 939-953

DOSI, G., (1988) Sources, procedures, and microeconomic effects of innovation. Journal of Economic Literature, 26, I I 20-I I 7 I.

DUNNING,J. H., (198I) Alternative channels and modes of international resource transmission, in: Sagafi, (eds.) Controlling international technology transfer: Issues, Perspective and Policy Implications. Pergamon, New York

EISENHARDT, K., ( 1989 ) Agency theory:An assessment and review. Academy of Management Review, I4, 57-74

ELIASSON, G., (1992) Business Competence, Organizational Learning and Economic Growth, in: F. Scherer and M. Perman (eds.), Entrepreneurship, Technological Innovation, and Economic Growth. University of Michigan Press, Ann Arbor

GARAVELLI,A.C., Gorgoglione, M., Scozzi, B., (2002) Managing knowledge transfer by knowledge technologies. Technovation ,22, 369-279

HAMERI,A., (1996) Technology transfer between basic research and industry, Technovation , 16, 51-57

HENDERSON, R.M., Clark, K.B., (I990) Architectural innovation: the reconfiguration of existing product technologies and the failure of established firms. Administrative Science Quarterly $35,9-30$.

HOBDAY, M.(1998) Product complexity, Innovation and Industrial Organization. Research Policy, 26, 689-719

HÖLMSTROM, B., ( 1979$)$ Moral Hazard and Observability, The Bell Journal of Economics, I0, 74-91.
HUGES,T., (1982) Network of Power : Electrification in western society, I800 1930, John Hopkins University Press.

HUR, K.I., Watanabe, C., (2002) Dynamic process of technology spillover; a transfer function approach, Technovation, 22, 437 444

KAMIEN M.I., Tauman.Y., (1986) Fees vs. Royalties and Private value of a Patent. The Quartely Journal of Economic, I0 I, 47 I-49 I.

KASSICIEH, K.S., Kirchhoff, A.B., Walsh, T.S., McWhorter, P.J,, (2002) The role of small firms in the transfer of disruptive technologies, Technovation 22, 667-674

KITCH, E.W., (1977) The Nature and Function of the Patent System. Journal of Law and Economics , 20, 265-290.

KIRSCHBAUM, R., (2005) Open innovation in practice. Research-Technology Management , 48, 24-28.

LAZONIK,W., (1993) Learning and the dynamics of international competitive advantage. In: R.Thomson (eds.). Learning and technological change, St. Martin's Press, New York, Pp. I72- 197

LEE, J., Win, H.N., (2004) Technology transfer between university research centers and industry in Singapore. Technovation, $24,433-442$

MACHO-STADLER, I.X. Martnez-Giralt, J.D. Pèrez-Castrillo, (1996) The role of Information in licensing contract design. Research Policy, 25, 43-57

MALERBA, F., Orsenigo, L., (1996) The dynamics and evolution of industries. Industrial and Corporate Change , 5, 5 I-87.

MALERBA, F., Orsenigo, L., (1997) Technological regimes and sectoral patterns of innovative activities. Industrial and Corporate Change , 6, 83-117.

MALERBA, F., Orsenigo, L., (1999) Technological entry, exit and survival, an empirical analysis of patent data, Research Policy , 28, 643-660

MARD, M., (2000a) Financial factors: cost approach to valuing intellectual property, Licensing journal, August, 27-28

MARD, M., (2000b) Financial factors: income approach to valuing intellectual property, Licensing journal, September, 27-30

MERGES, R., Nelson, R., (1990) On the Complex Economics of Patent Scope. Columbia Law Review , 90, 839-916. 
METCALFE, S., (1990) On diffusion, investment and the process of technological change. in: Deiaco E, Hornell E, Vickery G, Technology and investment crucial issues for the 1990s, Pinter Publishers, London

NELSON, R., Phelps, E., (1966) Investment in Humans, Technological Diffusion, and Economic growth, American Economic Review , 61, 69 75

NELSON, R.R.,Winter, S.G., (1977) In search of useful theory of innovation, Research Policy, 6, 36-76

NICHOLLS-NIXON, C., (1993) Absorptive capacity and technological sourcing: Implications for the responsiveness of established firms. Unpublished Ph.D. dissertation, Purdue University

NIOSI, J., Saviotti, P., Bellon, B., Crow, M., ( 1993) National system of innovation: In search of a workable concept, system of innovation, Technology in Society, I5, 207-227

NONAKA, I., (1994) A dynamic theory of organizational knowledge creation, Organizational Science , 5, 14-37

NONAKA, I., Takeuchi, H., (1995) The knowledge creating company. Oxford University Press, New York

PAVITT, K., (1984) Pattern of Technical Change: Toward a Taxonomy and a Theory, Research Policy , I 3, 343-273

PISANO, G., (1990) The R\&D boundaries of the firm: An empirical analysis, Administrative Science Quarterly , 35, I53-I76

POLANYI, M., (1966) The Tacit Dimensions, Doubleday Anchor, London

RADOSEVIC, S., (1999) International technology transfer policy: from "contract bargaining" to "sourcing". Technovation, 19 433-444

ROGENBERG, N., (1976) Perspective on Technology. Cambridge University Press, Cambridge

SAHAL, D., (198I) Patterns of Technological Innovation, AddisonWesley

SCHMOOKLER, J., (1966) Invention and Economic Growth . Harvard University Press.

TEECE, D., (1986) Profiting from technological innovation: implications for integration, collaboration, licensing and public po- licy. Research Policy , 15, 285-305.

TIROLE, J., (1989) The theory of industrial organization. The MIT Press., Boston

TUSHMAN, M.L., Anderson, P., (1986) Technological discontinuities and organizational environment, Administrative Science Quarterly 31, 439-465

TUSHMAN, M.L. Rosenkopf, L., (1992) Organizational Determinants of Technological Change:Toward a Sociology of Technological Evolution. Research in Organizational Behavior , I4, 3 II

\section{Biography}

Junyoung Kim received his BS degree at Yonsei University with a major in Mechanical engineering and MS degree in KAIST(Korea Advanced Institute of Science and Technology) with a major in Precision engineering and Mechatronics. After graduate school, he worked as an R\&D engineer and CTO(Chief Technology Officer) Staff manager for II years in Samsung Electronics Co. Ltd., in Korea. Now he is a Ph.D candidate in the Interdisciplinary Program of Technology Management in Seoul National University. And he is also a manager of Regional Technology Transfer Center at Incheon in Korea. He has both Certified Technology Value Advisor and Certified Technology Transfer Agent license in Korea.

Yongtae Park is a faculty member of the Department of Industrial Engineering at the Seoul National University (SNU). He holds BS in industrial engineering (from SNU), MS and PhD in operations management (both from University of WisconsinMadison). His research interests lie in areas of industrial knowledge network, knowledge management system, new product/service development, and on-line business modeling. Dr. Park has published numerous articles in, to name a few, Technovation, International Journal of Production Research, Decision Sciences, Technology Analysis and Strategic Management, R\&D Management, Technology in Society, Technology Forecasting and Social Change. 